\title{
1 An overview of subjectivist economics
}

The social object of skilled investment should be to defeat the dark forces of time and ignorance which envelop our future.

John Maynard Keynes (1964, p. 155; emphasis added)

That subjectivists of different schools, that is to say, all those who view the market as a pattern of meaningful utterances of the human mind, will in the future be able to find common ground seems to us to lie distinctly within the realm of possibility.

Ludwig M. Lachmann (1984, pp. 13-14)

This book began as an attempt to survey and restate the basic features of "Austrian" economic theory. As we examined the fundamental presuppositions of the theory, however, we realized that in order to accomplish our task we had, in a sense, to go beyond it. At the very heart of Austrian economics lies a common ground with some other schools of economic thought. This common ground has long been recognized as the essence of the Austrian contribution to economics: subjectivism. For most economists, unfortunately, subjectivism denotes either exclusively the supposedly complete subjective theory of value or the idea that scientific theories should be personal and hence never subject to testing. Both meanings are, however, thoroughly inaccurate.

On the most general level, subjectivism refers to the presupposition that the contents of the human mind, and hence decision-making, are not rigidly determined by external events. Subjectivism makes room for the creativity and autonomy of individual choice. Dealing as it does with the individual mind and individual decision-making, it is also intimately related to methodological individualism. This is the view that overall market outcomes ought to be explained in terms of individual acts of choice. Thus, for the Austrians, and for subjectivists generally, economics is first and foremost about the thoughts leading up to choice, and not about things or the interaction of objective magnitudes (Morgenstern, 1972, p. 702, Shackle, 1972, p. 66).

In this chapter we first examine the basic implications of subjectivism for economic theory. We then discuss the importance of these implications. In a third section we outline the common ground between Austrians and (post-)

DOI: $10.4324 / 9781315776736-6$ 
Keynesians while, at the same time, recognizing the unique Austrian contributions to subjectivist economics. Finally, we briefly discuss the contents of the remaining chapters.

\section{Time and ignorance}

The relative autonomy of individual choice clearly implies the imperfect predictability of the future consequences of choices. When an individual decides to embark upon a particular course of action, the consequences will depend, in part, on what courses of action other individuals are, or will be, choosing. A world in which there is autonomous or creative decision-making is one in which the future is not merely unknown, but unknowable. There is nothing in the present state of the world that enables us to predict the future state because the latter is underdetermined by the former. (This, of course, does not preclude the analyst from, ex post, making the once-future intelligible on the basis of what happened in the past.) Subjectivism and action under uncertainty are thus inseparable ideas.

There are two complementary ways of conceptualizing the unknowability of the future. The first is to develop the dynamic conception of time (variously known as "real," "historical," or "subjective" time). The other is to explicate the notion of ignorance and its corollary, radical or "genuine" uncertainty. We begin with a discussion of real time.

\section{Real time}

In a certain respect, neoclassical economics has not changed much in the past 50 years. Many of the recent "innovations" in theory simply extend the static maximizing apparatus to allegedly dynamic issues. In particular, time is still most frequently conceived in purely static terms. As such, it is analogized to space: just as an individual may allocate portions of space (land) to certain purposes, he can also allocate portions of time to certain activities. In principle, time and perfect predictability are compatible. The dynamic conception of time, on the other hand, is time perceived as a flow of events. Implicit in this idea of a flow is that of novelty or true surprise. The individual's experience of today's events itself makes tomorrow's perceptions of events different than it otherwise would be. As an individual adds to the stock of his experiences, his perspective changes and so both the present and the future are affected by the past flow of events. Flows, however, are continuous, and hence the individual's perspective changes right up to the moment of any experience. This renders perfect prediction of the experience impossible. Since all individuals are similarly affected, and since, as we have seen, the consequences of an individual's course of action depend on what others will do, this idea of time has implications for decision-making. Choices made in real time are thus never made with complete knowledge (either deterministic or stochastic) of their consequences. The recognition of this 
fact by individuals is the source of rule-following behavior and, on a social level, of the development of institutions. We have more to say on this later in the chapter and in future chapters.

\section{Ignorance}

In all variants of neoclassical economics there is a presumption of knowledge on the part of economic agents. In its older form the presumption was of perfect knowledge and foresight, and in its more recent form it has been that of perfect stochastic knowledge and foresight. Thus, 30 years ago agents knew with certainty the price charged for a given product in both the current period and in all future periods; today, on the other hand, they are likely to know the probability distribution of current prices and the underlying stochastic structure that generates future prices. Even when agents are assumed not to know the complete probability distribution, such a distribution is hypothesized to "exist" in some objective way. This is then used as the basis of a story about how individuals gradually learn the distribution. None of these approaches, however, captures the idea of ignorance in the sense intended by subjectivists. Ignorance is not something that, at least at some level, can be avoided or overcome. It is not a state of imperfect knowledge that some process asymptotically eliminates. As long as we remain in a world of real time, unexpected change is inevitable and ignorance is ineradicable. Subjectivists therefore are not in sympathy with analytical devices that eliminate this object of study. Ignorance should not be transformed into a variant of knowledge.

The neoclassical method of modeling uncertainty essentially denies the fundamental tenet of subjectivism: the autonomy of individual choice. To portray the uncertain future as an objective probability distribution defined over an exhaustive set of events is to make the claim that the future is merely unknown. Thus, it is in principle knowable because the future exists out there independently of the autonomous choices of individuals. Or, to put it another way, the neoclassical modeling techniques abolish the autonomy of the human mind. This is the central problem inherent in most formulations of rational expectations equilibria.

The movement toward a "subjectivist" theory of probability in some areas of economics has no doubt been an improvement from our perspective. Yet most of this literature neglects a fundamental aspect of ignorance: the (perceived) unlistability of all possible outcomes. It is not merely that we do not know which possibility out of a given set will occur, but the set itself is unbounded. Subjective probability thus reflects subjectivism in its static form; while unbounded possibility sets reflect the essentially dynamic aspect of subjectivism. Real time and ignorance belong together.

\section{The importance of time and ignorance}

Does any of this matter? A critic might admit that real time and ignorance do describe aspects of the world in which we live, but he might claim that 
they are unimportant (or even counterproductive) from the perspective of deriving useful economic implications. Most of the rest of this book is, in effect, an answer to this hypothetical critic. We hope to show in very detailed fashion that subjectivism has important implications for economic theory and, ultimately, for applied economics. It is, however, important to make clear that contemporary economics overemphasizes the importance of "useful implications." This is the consequence of an essentially instrumentalist view of social science. The presupposition is that we really know nothing about individual decision-making, aside from what can be corroborated in econometric tests of aggregative (market) data. We reject this naive instrumentalism (Caldwell, 1982, pp. 173-88). While the implications for overall market behavior are important, it is also important to be faithful to the structure of human action as we know it to exist (Mises, 1966, pp. 11-29, 92-142; Rothbard, 1970, pp. 1-66). In this sense, we try to steer a middle course between pure apriorism and pure instrumentalism.

The most fundamental or general implication of time and ignorance, to which we have already alluded, is that economics must abandon its traditional static mold. "[A] theory which takes serious account of time and ignorance must be a theory of processes, not of states - not even dynamic states" (Loasby, 1976, p. 220). Since all action takes place in real time and under genuine uncertainty, the actions of individuals are unlikely to be perfectly coordinated. This means, of course, that people will be frustrated in efforts to achieve their goals. Hence all market activity, as the outgrowth of individual goal-directed action, can be rendered intelligible as a process of attempting to correct errors and coordinate behavior. This process will obviously fail at times, and economics must also concern itself with the forces that promote error and discoordination. Sometimes these forces will be the result of purely exogenous changes in the "data," but at other times they will be the result of endogenous changes. Thus, the market process is literally unending.

Time and ignorance not only make economic processes necessary, they also affect the very character of these processes. A process economics differs from one incorporating dynamic states insofar as the former is not deterministic. There is no stable endpoint toward which the process must lead, nor a single path that it must follow. At least on a general level, our view shares much in common with that of Nelson and Winter (1982), who have developed a nondeterministic evolutionary economics. In their approach, as in ours, error and the correction of error are important facets in the dynamic process. In counterdistinction to the neoclassical approach, however, these errors do not wind down to a determinate equilibrium state. Thus, we have process or evolution without traditional equilibria.

A second extremely important effect of the explicit recognition of time and ignorance is a shift away from modeling all behavior as the result of mathematical maximization. The unboundedness of expectations - or, more specifically, of the possibilities and choice set envisaged by the actor - means that traditional maximization techniques are inapplicable (Loasby, 1976, p. 217). 
Consequently, actors are more appropriately modeled as following rules of thumb or "routines" (Nelson and Winter, 1982, pp. 14-21 and passim) at one end of the behavioral continuum, or as engaging in entrepreneurial discovery at the other end (Kirzner, 1973, 1979a).

In the first case, many different perceptions of the environment, as well as different expectations, are each consistent with the same pattern of behavior. Rules provide, as it were, safe bounds for behavior in a relatively unbounded world. Institutions are the social crystallization of rule-following behavior or, in other words, the overall pattern of many individuals following a similar rule (Hayek, 1973, pp. 35-54). Thus, the circle is closed. Time and genuine uncertainty promote the following of rules and the development of institutions. The latter, in turn, serve to reduce, but not eliminate, the unboundedness of the economic system by providing the stable patterns of interaction.

In the second case, entrepreneurial discovery can be seen as an attempt to fill coordinative gaps in the system that arise from the existence of time and ignorance. At the individual level, entrepreneurship consists of going beyond a given means-ends framework; it is the act of altering or creating the framework by discovering new ends and means. At the market level, entrepreneurs strive to discover (or create) possibilities that have been generally overlooked by other market participants. Entrepreneurs are, however, themselves subject to the effects of time and ignorance, and hence may often commit errors. These errors can be the source of further unpredictability and instability in the system. Nevertheless, it seems reasonable to believe that a world without profit-seeking entrepreneurial behavior is likely to be more unpredictable and unstable than a world with it.

A third implication of taking time and ignorance seriously is a greater emphasis on spontaneous or unintended consequences of individual action. Neoclassical economics in its purest form is uncomfortable with the idea of spontaneous consequences. Wedded as it is to one or more species of knowledge, it strives to explain as many market phenomena as possible as the intended outgrowth of individual optimizing. In the economic analysis of law, for example, certain judge-made legal doctrines have been rationalized as promoting efficiency. While the process by which this supposedly comes about is somewhat mysterious, there is a clear implication that judges, at least implicitly, want it that way (Posner, 1977, pp. 15-191). Similarly, in at least one variant of the economics of the political process, tariffs, agricultural subsidies, minimum wages, and the like exist because they are efficient adaptations to individuals' redistributional demands (Peltzman, 1976; Becker, 1976b). Many, though not all, neoclassical rationalizations of aggregative phenomena are thus rooted in the view that "people get what they want."

The subjectivist research program, on the other hand, is to explain overall outcomes as the spontaneous, unintended product of social interactions. Under conditions of ignorance, no individual can predict fully the consequences of a chosen course of action. Hence he is bound to be at least somewhat surprised by the ultimate (aggregate) outcome. The world looks as if it 
is no part of his doing. The interaction of individuals' courses of action, the market process, is thus a kind of discovery procedure (Hayek, 1978). Through the knowledge that is revealed to him by this process each agent is able to surpass the limits of his own ignorance. No one individual or firm needs to know, or can know beforehand, how best to organize production, what products to produce, or even what raw materials to use. In the course of acting, an individual will learn more about the "environment" in which he operates.

The idea of spontaneous consequences and market discovery has significance for economic policy. It leads us away from the presumption that we can always improve matters by merely applying our (i.e., the planner's) given knowledge in the most efficient way. This is the view Hayek (1965) has called "constructivism." In contrast, Austrian subjectivists would argue that state economic planning deprives society of the knowledge gained through the market process and of the ability to surpass the limitations of individual knowledge (Lavoie, 1985). Thus, the ignorance of the individual constrains action at the central planning level to a far greater extent than at the market level.

\section{Keynesianism and the Austrian contributions}

\section{Keynes}

It is clear from the first epigraph of this chapter that Keynes was no stranger to the economics of time and ignorance. Recognition of the power of the "dark forces" was central to his conception of the economic system. In the first instance, the "state of longterm expectations," which is important in determining the rate of investment, might "be subject to [autonomous] waves of optimistic and pessimistic sentiment ... where no solid basis exists for a reasonable calculation" (Keynes, 1964, p. 154). As we have seen, a "reasonable" or, more exactly, an optimizing calculation is not possible in an unbounded context. In addition, Keynes saw the importance of subjectivism for shortrun output decisions which are influenced by user cost. "User cost" is "the reduction in the value of ... equipment due to using it as compared with not using it" now "and preserving it to be used later on" (1964, p. 70). The calculation of user cost obviously depends upon subjective guesses as to the future state of the market. Keynes sometimes also recognized that individual choice is the pivotal distinction between the natural and social sciences. In an important letter to Sir Roy Harrod, he said that, if the natural sciences were to be treated as the social sciences, then "it [would be] as though the fall of the apple to the ground depended on the apple's motives" (Keynes, 1973, p. 300).

Despite the evidence presented above, it is only quite recently that the subjectivist aspects of Keynes' thought have been more widely recognized. In part, this is because the reformulation of his work in general equilibrium terms, arising out of the neoclassical synthesis, obliterated the subjectivist 


\section{The economics of time and ignorance}

component (Davidson, 1981, p. 159). More importantly, perhaps, there exists a deep contradiction in the General Theory itself between the mechanical, aggregative method and the nonformalized subjectivist message (Lachmann, 1984, p. 7). Unfortunately, Keynes never resolved this contradiction, and thus it prevented him from seeing the full implications of subjectivism. His statement about the dark forces of time and ignorance was made in the context of advocating government management of major investment decisions. $\mathrm{He}$ apparently never saw the limitations that real time and ignorance place on policy-makers.

\section{Post-Keynesianism}

In recent years a largely American branch of the Cambridge (UK) school, known as post-Keynesian economics, has arisen to carry forth the subjectivist aspects of Keynes' system. For a long time these had been buried and almost forgotten within the Hicksian neoclassical synthesis. Now, fortunately, they are being revived and developed. Paul Davidson has conveniently summarized the post-Keynesian perspective in three propositions (1981, pp. 158-61):

(1) the economy is a process in historical (real) time;

(2) in a world where uncertainty and surprises are unavoidable, expectations have an unavoidable and significant effect on economic outcomes;

(3) economic and political institutions are not negligible and, in fact, play an extremely important role in determining real-world economic outcomes.

The reader will be hard pressed to find any significant differences between these propositions and the argument of this chapter. What is even more surprising is that Davidson's explication of the meaning of these propositions increases, rather than reduces, the area of overlap. It is evident that there is much common ground between post-Keynesian subjectivism and Austrian subjectivism. Cross-fertilization between these two schools is, however, exceedingly rare, although the possibilities for mutually advantageous interchange seem significant.

\section{Austrian contributions}

We have already discussed what may be the most important distinctive contribution of the Austrian variant of subjectivism. Austrians have stressed the view of the market process as an engine of discovery. Just as real time implies genuine uncertainty about the future, it equally implies that truly novel things can be learned by economic agents. One interpretation of the statement that we live in a world of real time and ignorance is simply that we cannot predict the knowledge we shall gain in the future (Popper, 1964, pp. vi-vii). Learning, for Austrians, is not merely plugging in new values of variables in an otherwise unchanged learning function. It involves a structural 
shift in knowledge, i.e., a change in the learning functions themselves. The market process is both the source and the manifestation of these structural changes. In the absence of such a process, economic planners must address the question of how they can acquire the requisite information necessary to implement their plans successfully.

There are other distinctive Austrian contributions to subjectivist economics. These, however, are less easy to state in summary fashion, but some will be examined in greater detail later in this book. Austrians have made fundamental contributions to, among other areas, interest theory (Fetter, 1977; Rothbard, 1970, pp. 313-86), capital theory (Lachmann, 1956; Kirzner, 1966), the theory of money (Mises, 1953; White, 1984), competition and entrepreneurship (Kirzner, 1973; 1979), and business cycle theory (Hayek, 1969; O’Driscoll, 1977; Wainhouse, 1982). The common thread underlying all of these analyses is the extension of subjectivism beyond the point to which it had previously been developed. This is not to say that in all of these areas the subjectivist approach has been completed or is fully adequate. It is rather to claim that the subjectivist ideas of time and ignorance have been infused into the analyses in a way that changes the basic questions and issues.

\section{Overview of the rest of the book}

This book (appearing here as Part III) is divided into two sections. In Section I we present, in more detailed fashion, the analytical framework that we sketched in this chapter. We discuss subjectivism, knowledge, decisions, time, uncertainty, and equilibrium. In Section II we apply this theoretical framework to specific economic subject areas such as competition and monopoly, political economy, capital theory, and monetary theory. In neither section will the reader find much in the way of explicit formal modeling. This reflects a conscious decision by the authors. In the first place, we believe that presenting the conceptual foundations of our approach is both logically and heuristically prior to any modeling effort. Second, and perhaps more important, many of the formal analytical tools used by economists today necessarily preclude the phenomena in which we are interested. In fact, one of the reasons contemporary economics is still fundamentally static is that the mechanics of optimization and the standard assumptions of equilibrium are not consistent with genuine process analysis.

\section{Framework}

In the next chapter we distinguish our concept of subjectivism from the older, static idea that derives from the subjective theory of value. In so doing, we discuss the meaning of creative choice and the role of nondeterministic explanation. Our general conclusion is that we must avoid both the position that creative choice is impossible, and the position that all choice is creative 
and unbounded. Creativity can exist only within a framework that provides at least some degree of predictability.

In Chapter 3 we analyze the problem of knowledge from a subjectivist perspective. Foremost among the issues we discuss are the nature and process of learning, the difference between knowledge of economic actors and knowledge of the scientist, the division of knowledge in society, and the role of knowledge in institutions. The chapter concludes with a re-examination of utility theory. Here the subjectivity of both blades of the Marshallian scissors (utility and cost) is explained and applied to a disequilibrium context.

Chapter 4 is a detailed examination of the differences between "Newtonian" (analytic or static) time and the dynamic conception that we have already briefly mentioned. We discuss the role of each concept of time in specific economic models. In particular, we examine the implications of real time for the study of economic processes. The chapter concludes with a discussion of the conceptual relation between Newtonian and real time.

The fifth chapter explores the most important implication of ignorance: genuine uncertainty. Here the interrelation between uncertainty and equilibrium is explored. We find that genuine uncertainty is incompatible with traditional ideas of equilibrium, including that of stochastic equilibrium. In this context we spend a good deal of time analyzing the "endogenous" uncertainty in Keynes' famous beauty contest and Morgenstern's Holmes-Moriarty story. An alternative equilibrium construct is proposed ("pattern coordination") that is consistent with endogenous or genuine uncertainty.

\section{Applications}

Chapter 6 is a detailed study of our claim that the market process is a discovery procedure. We trace the logical evolution of the concept of competition from that of a state of affairs to a process of attaining or approaching equilibrium to, finally, a ceaseless "mechanism" of discovery. We then go on to show that market processes, in the widest sense, consist not only (or even primarily) of optimizing behavior but also of rule-following behavior. The latter is, of course, ultimately related to the social role of institutions. Both rules and institutions are, in turn, as we have seen, consequences of the conditions of ignorance under which individuals face the future.

In Chapter 7 we apply the theoretical structure developed in the previous chapter to a number of important issues in political economy. Real time, ignorance and genuine uncertainty, as we have seen, have significant implications for economic policy. In this chapter we apply those general insights to pollution control through tax policy and to antitrust regulation. Our general conclusion is that much regulation, in order to be effective, presupposes the kind of knowledge available only through market processes. Paradoxically, then, the regulators need the very process that their regulation is, at least in part, designed to supplant. 
Chapter 8 applies subjectivist ideas to the theory of capital goods and associated "macro" and monetary issues. The Austrian concept of a production structure is introduced and the nature of capital complementarities within that structure is explored. The heterogeneity of capital goods is shown to be crucial to any theory of economic processes. Specifically, the whole process of capital recombinations or changes in the production structure is obliterated by neoclassical theories of capital homogeneity. In those theories there is nothing to recombine and no production structure to change. Therefore, subjectively perceived differences in capital goods are intimately related to the dynamic market process.

Chapter 9 begins with an analysis and application of the Mengerian theory of the origin of money. As we shall see, Menger's theory embodies almost every important aspect of subjectivist economics: methodological individualism, emphasis on expectations, and a market process of discovery. One important conclusion we draw from his theory is that even a basic economic institution like money is a part of the ongoing market process. Hence, attempts by government to modify or regulate monetary institutions must take account of this process. The final part of Chapter 9 discusses the Wicksell-Mises-Hayek theory of economic fluctuations. Here the subjectivist theory of capital goods and the production structure, developed in Chapter 8 , is integrated with a theory of the cycle. The chapter concludes with a review of new evidence corroborating the Austrian cycle theory, as well as an analysis of the relevance of rational expectations to this theory.

Chapter 10 is a concluding chapter in which we identify some areas of future research and suggest applications of the approach developed in the previous nine chapters. 